\title{
Preparation of Turkey Pox Vaccine in SPF Eggs
}

\author{
Olfat E. Nakhla; Manal Awad; Soad M. Soliman, A. Michael \\ Veterinary Serum and Vaccine Research Institute, Abbasia, Cairo, Egypt.
}

\begin{abstract}
An identified local virulent Egyptian strain of turkey pox virus (TPV) was attenuated on specific pathogen free (SPF) embryonated chicken eggs (ECE) for production of specific turkey pox vaccine. Forty serial passages of the virus were applied on the chorioallantoic membrane (CAM) of SPF ECE, so titration of the serial passages were undergone in which the highest titres $\left(10^{7.0}, 10^{7.1}\right.$ and $10^{7.1}$ EID $\left._{50} / \mathrm{ml}\right)$ were recorded for the passages 30,35 and 40 , respectively.

The pathogenicity of the $10^{\text {th }}, \mathbf{2 0}^{\text {th }}, \mathbf{3 0}^{\text {th }}$ and $40^{\text {th }}$ passages were tested by inoculation in susceptible turkeys. The passage of $30^{\text {th }}$ and $40^{\text {th }}$ passages produced the most acceptable post vaccinal reaction (pvr) beside giving the highest virus titre of the attenuated passages. The selected field dose which gave only takes (swelling of the skin) at the site of injection in susceptible turkeys and withstood challenge with the virulent turkey pox virus one month later was $10^{4.0} \mathrm{EID}_{50} / \mathrm{ml}$. The prepared vaccine tested for sterility, safety and potency tests and proved to be potent for the vaccinated turkeys which resisted the challenge for 9 months post vaccination.

Antibody levels in the serum of vaccinated turkeys were estimated by serum neutralization test, where neutralizing antibodies expressed as neutralizing index were appeared from the $1^{\text {st }}$ week (1.0 NI) and reached its peak on the $3^{\text {rd }}$ week (2.2 NI) post vaccination.
\end{abstract}

Avian pox is a common viral disease of domestic birds (chicken, turkeys, pigeons and canaries) and is worldwide distributed and infects birds of all ages and breeds (Karustad, 1971; Odend'hal, 1983). Turkey pox virus is one of Avipox viruses which is characterized by the development of discrete nodular proliferative skin lesions on the non-feathered parts of the body (cutaneous form) and fibrino-necrotic and proliferative lesions in the mucous membrane of the upper respiratory tract, mouth and oesophagus, the diphtheritic form (Esposito et al., 1991).

The economic importance of pox infection in turkeys is attributed to retardation of weight, blindness, decreased egg production and impaired fertility (Tripathy and Reed, 1997).

The course of the disease in turkey flocks may be 2-3 weeks and severe outbreaks often last 6,7 or even 8 weeks with high mortalities reaching $50 \%$ of the infected birds (Winterfield et al., 1985).

Fowl pox vaccine is used to vaccinate turkeys against pox infection by the wing-web method, but the virus may spread and infect the head region causing generalization of the pox disease (Tripathy and Reed, 1997). So, the main goal of the present study is to prepare specific turkey pox vaccine from the local Egyptian isolate in SPF embryonated chicken eggs, which is a homologous vaccine producing higher protection percent than the heterologous one.

\section{Materials and methods}

Turkey pox virus. A local strain of turkey pox virus was previously isolated, identified and characterized in specific pathogen free (SPF) embryonated chicken eggs of 9-11 days old (Nakhla Olfat and Daoud, 2004) and its titre was $10^{5.5} \mathrm{EID}_{50} / \mathrm{ml}$.

Embryonated chicken eggs. Five hundred (SPF) embryonated chicken eggs of 9-11 day old were obtained from Kom-Osheim SPF Farm, Fayoum, Egypt. They were used for propagation, attenuation and titration of the local strain of turkey pox virus.

Susceptible turkeys. One hundred and sixteen susceptible turkeys poults aged 45 days old were used, for evaluation of pathogenicity, safety and potency of the prepared vaccine. These turkeys were divided as follows.

-Twenty turkeys were used for determination of the pathogenicity of the attenuated turkey pox virus.

-Sixteen turkeys were used for detection of the protective dose.

-Twenty turkeys were used for testing the safety of the prepared vaccine.

-Sixty turkeys were used for detection of the potency and duration of immunity. 
Table (1): Titration of turkey pox virus on chorioallantoic membrane (CAM) of (SPF) embryonated chicken eggs

\begin{tabular}{cccccccccc}
\hline Number of passage & 0 & 5 & 10 & 15 & 20 & 25 & 30 & 35 & 40 \\
\hline Titre in $\log _{\mathbf{1 0}} *$ & 5.5 & 5.7 & 6.0 & 6.5 & 6.8 & 7.0 & 7.0 & 7.1 & 7.1 \\
\hline
\end{tabular}

* The titre was expressed in $\mathrm{EID}_{50} / \mathrm{ml}$ and calculated with Reed and Muench (1938).

Stabilizer. Lactalbumin sucrose stabilizer $(5 \%$ lacalbumin hydrolysate and $2.5 \%$ sucrose) was prepared according to the OIE (2000).

Serum samples. Blood samples were collected for sera through wing vein from all turkeys before vaccination and weekly after vaccination and challenge for detection of antibody levels by serum neutralization test.

Attenuation and titration of the virulent turkey pox virus in SPF embryonated chicken eggs. Serial passages of turkey pox virus were done and titrated on the chorioallantoic membrane (CAM) of fertile SPF eggs according to Pandey and Mallick (1975). The EID ED $_{50}$ was calculated according to Reed and Muench (1938) and the results recorded in table (1).

Determination of the pathogenicity of the attenuated turkey pox virus in susceptible turkeys poults. Pathogenicity test was carried out according to Frank et al., (2001) on passages $10^{\text {th }}, 20^{\text {th }}, 30^{\text {th }}$ and $40^{\text {th }}$ of attenuated turkey pox virus. Four susceptible turkeys for each passage were inoculated by wing web route and left four turkeys as non-inoculated control. The inoculated birds were kept under observation for 15 days for appearance of local and general post inoculation reaction.

Selection of the protective dose. According to Box (1984), dilutions $10^{-2}, 10^{-3}$ and $10^{-4} \mathrm{EID}_{50} / \mathrm{ml}$ from the $40^{\text {th }}$ passage; that having titre of $10^{7.1}$ EID50/ml were inoculated by wing web method in four susceptible turkeys poults for each dilutions, another four turkeys poults were left as non-vaccinated control. Challenge was carried out on all birds with virulent turkeys pox virus by wing web route, one month post inoculation (Table 2).

Preparation and lyophilization of the adapted turkey pox virus. The selected passage was lyophilized after addition of lactalbumin sucrose stabilizer in a ratio $1: 1$ and was submitted to freeze drying process (according to Mayr, 1962). Evaluation of the prepared turkey pox vaccine.

Sterility. It was carried out according to OIE (2000), by using nutrient agar, Sabouraud's, thioglycolate medium and mycoplasma media for any bacterial or fungal contamination. Also, they were tested for any extraneous viruses.

Safety. According to OIE (2000), five susceptible turkeys were inoculated with the selected protective dose of the prepared vaccine $\left(10^{4} \mathrm{EID}_{50} / \mathrm{ml}\right)$ and another five turkeys were inoculated with 10 times of such dose. Five turkeys were kept as a contact control and another five were kept as an isolated control group for one month.

Potency test and duration of immunity. Forty susceptible turkeys were vaccinated with the field dose of the prepared vaccine by wing web route according to Frank et al., (2001) and 20 non-vaccinated control turkeys were used. Challenge was carried out with the virulent turkey pox virus $(\mathrm{TPV})\left(10^{5.5} \mathrm{EID}_{50} / \mathrm{ml}\right)$ by wing web route $(0.025 \mathrm{ml})$ in 8 vaccinated and 4 susceptible control turkeys at 1, 3, 5, 7, 9 months post vaccination with collection of serum samples from the birds.

\section{Serological assay.}

Serum neutralization test (SNT). Antibody response was estimated using serum neutralization test as recommended by Buscaglia et al., (1985).

\section{Results}

The local isolate of turkey pox virus was passaged on the CAM of SPF-ECE resulted in less extensive diffuse pock lesions and pale yellow in colour. The titres were recorded in table (1).

Different dilutions $10^{-2}, 10^{-3}$ and $10^{-4}$ $\mathrm{EID}_{50} / \mathrm{ml}$ from the $40^{\text {th }}$ passage; that having titre of $10^{7.1}$ EID50/ml were prepared and inoculated by wing web into turkeys poults, in addition to 4 susceptible non-vaccinated ones. They were challenged with virulent TPV and the results were recorded in table (2).

The results of vaccination of eight susceptible poults and their challenge with four susceptible controls using virulent TPV at 1, 3, 5, 7 and 9 months post vaccination were stated in table (3).

The immunological response of poults vaccinated with the prepared turkey pox vaccine and challenged with virulent TPV, was estimated by serum neutralization test (SNT). The results were presented in table (4). 
Table (2): Selection of the protective field dose.

\begin{tabular}{cccc}
\hline Number of turkeys & Dilution & Challenge result * & Protection \% \\
\hline $\mathbf{4}$ & $10^{-2}$ & $0 / 4$ & $100 \%$ \\
$\mathbf{4}$ & $10^{-3}$ & $0 / 4$ & $100 \%$ \\
$\mathbf{4}$ & $10^{-4}$ & $1 / 4$ & $75 \%$ \\
$\mathbf{4}$ & Controls & $4 / 4$ & $0 \%$ \\
\hline
\end{tabular}

*Number of turkeys showing pox lesions

N.B. Vaccinated and control turkeys were considered infected when showing typical local and generalized pox lesions after challenge with virulent turkey pox virus

Table (3): Potency test and duration of immunity from turkey pox vaccine.

\begin{tabular}{|c|c|c|c|c|c|c|c|c|c|c|}
\hline \multirow{3}{*}{$\begin{array}{l}\text { Turkey } \\
\text { group }\end{array}$} & \multicolumn{10}{|c|}{ Results of challenge test } \\
\hline & \multicolumn{2}{|c|}{$1 \mathrm{MPV}$ * } & \multicolumn{2}{|c|}{3 MPV } & \multicolumn{2}{|c|}{$5 \mathrm{MPV}$} & \multicolumn{2}{|c|}{$7 \mathrm{MPV}$} & \multicolumn{2}{|c|}{$9 \mathrm{MPV}$} \\
\hline & $\begin{array}{c}\text { NRT/NVT* } \\
*\end{array}$ & $\begin{array}{l}\text { Prot } \\
. \%\end{array}$ & $\begin{array}{c}\text { NRT/NV } \\
\text { T }\end{array}$ & $\begin{array}{l}\text { Prot } \\
. \%\end{array}$ & $\begin{array}{c}\text { NRT/NV } \\
\text { T }\end{array}$ & $\begin{array}{c}\text { Prot } \\
. \%\end{array}$ & $\begin{array}{c}\text { NRT/NV } \\
T\end{array}$ & $\begin{array}{l}\text { Prot } \\
. \%\end{array}$ & $\begin{array}{c}\text { NRT/NV } \\
\text { T }\end{array}$ & $\begin{array}{c}\text { Prot } \\
. \%\end{array}$ \\
\hline $\begin{array}{c}\text { Vaccinate } \\
\text { d }\end{array}$ & $0 / 8$ & 100 & $0 / 8$ & 100 & $0 / 8$ & 100 & $1 / 8$ & 88 & $1 / 8$ & 88 \\
\hline Control & $4 / 4$ & 0 & $4 / 4$ & 0 & $4 / 4$ & 0 & $4 / 4$ & 0 & $4 / 4$ & 0 \\
\hline
\end{tabular}

* MPV: Months Post Vaccination.

** NRT/NVT: Number of reacted turkeys / Number of vaccinated turkeys. Prot. \%: Protection \%.

Table (4): Results of serum neutralization test of turkey sera vaccinated with turkey pox vaccine.

\begin{tabular}{|c|c|c|}
\hline \multirow{2}{*}{$\begin{array}{l}\text { Weeks post } \\
\text { vaccination }\end{array}$} & \multicolumn{2}{|c|}{ Mean neutralizing index (NI) } \\
\hline & Vaccinated & Control \\
\hline 0* & 0.3 & 0.3 \\
\hline 1 & 1.0 & 0.4 \\
\hline 2 & 1.4 & 0.4 \\
\hline 3 & 2.2 & 0.4 \\
\hline $4 * *$ & 2.0 & 0.5 \\
\hline 5 & 1.9 & 1.1 \\
\hline 6 & 1.7 & 1.8 \\
\hline 7 & 1.6 & 1.9 \\
\hline
\end{tabular}

N.B. Mean neutralizing index (NI) was considered protective when it was $>1.5$

\section{Discussion}

As for most viral diseases, vaccination is the sole option for combating infectious agents and vaccines in poultry production are used to prevent or reduce problems that can occur from the infection. So, production of specific turkey pox vaccine which produces solid immunity to turkeys against pox infections is important where fowl pox vaccine which is used cause infection of turkey's head which cause spreading of pox infection to the whole flock (Tripathy and Reed, 1997).

Since the usual technique for developing an avian pox vaccine was applied by serial passages of the virulent isolate in specific pathogen free (SPF) embryonated chicken eggs (Tripathy and Reed, 1997), the local isolate of turkey pox virus was propagated and attenuated on the chorioallantoic membrane (CAM) of SPF embryonated chicken eggs for 40 passages. The virus produced lesions were less extensive diffuse and pale yellow in colour which was in agreement with Kar and Pathak (1980). The titres of the different passages were recorded in table (1) showed that pock lesions on CAM appeared more clearly and increased by the passage and the highest virus titre $\left(10^{7.1}\right.$ $\mathrm{EID}_{50} / \mathrm{ml}$ ) was highest and steady for the passages 35 and 40 .

In pathogenicity test; the characteristic lesions of the cutaneous form of pox in turkeys were clearly observed in the $10^{\text {th }}$ passage and decreased by the $20^{\text {th }}$ passage. With the passages number 30 and 40 "takes" consist of swelling of 
the skin or a scab at the site of inoculation which appeared about 7-10 days after inoculation as that recorded by (Saini et al., 1990; Tripathy and Reed, 1997).

Results in table (2) showed that the used dose $\left(10^{4} \mathrm{EID}_{50} / \mathrm{ml}\right)$ was able to produce solid immunity against challenge with virulent turkey pox, which was in agreement with (Gelenczei and Lasher, 1968).

The prepared vaccine proved to be free from any bacterial and fungal contaminations. Also, the vaccine is considered safe as no post vaccinal reaction in both groups either inoculated with field dose $\left(10^{4} \mathrm{EID}_{50} / \mathrm{ml}\right)$ or with 10 times dose, the result fulfill the recommendation of OIE (2000).

Potency tests (vaccination, challenge and duration of immunity) as recorded in table (3) concluded that vaccinated turkeys with the produced vaccine were protected against the challenge with the virulent TPV till 9 months (where $88 \%$ protection, while $0 \%$ in nonvaccinated control), was recorded. The result is in agreement with Frank et al., (2001).

The neutralizing indexes of vaccinated turkeys (table 4) were observed from the $2^{\text {nd }}$ week post vaccination (1.4 NI) and became protective from the $3^{\text {rd }}$ week $(2.2 \mathrm{NI})$. All the vaccinated turkeys showed a little decrease in the NI in the $1^{\text {st }}$ week post challenge (1.9 NI) due to partial vaccinal virus antibodies, while in the control non-vaccinated turkeys, the neutralizing index reached its highest level by the $3^{\text {rd }}$ week (1.9 NI) post challenge.

In conclusion, the local virulent turkey pox virus could be attenuated in SPF-ECE and used as safe potent vaccine and this vaccine can be used to improve turkey industry which play an important role in meat production and used locally and for exportation.

\section{References}

Box, P.G. (1984): Poultry vaccines. Live or killed. Poult. Inter., May: 58-66.
Buscaglia, C.; Bankowski, R.A. and Miers, L. (1985): Cell culture virus neutralization test and enzyme linked immunosorbent assay for evaluation of immunity in chickens against fowl pox. Avian Dis., 29 (3): 672-680.

Esposito, J.J.; Baxby, D.; Black, S.; Dales, G.; Darai, K.; Dumbell, R.; Grandos, W.K.; Joklik, G.; McFadden, B.; Moss, R.; Moyer, D.; Pickup, A.; Robinson, H.; Rouhandeh and Tripathy, D. (1991): Classification and nomenclature of viruses, Family Poxviridae. Springer Verlog Wein, New York, pp. 91-102.

Frank, J.; Mark, P.; Dennis, A. and Trevor, F. (2001): Poultry Diseases. Vaccines and Vaccination, 4: 55-70.

Gelenczei, E.F. and Lasher, H.N. (1968): Comparative studies of cell culture propagated avian viruses in chickens and turkeys. Avian Dis., 12: 142-149.

Karustad, L. (1971): Infectious and parasitic diseases of wild birds. Pox, 34-41.

Kar, B.C. and Pathak, R.C. (1980): Cultivation and titration of some avian viruses in developing chick embryo. Ind. Vet. J., 57 (2): 99-103.

Mayr, A. (1962): Keeping quality of poultry pox viruses. Mh. Tierheilk, 14: 332-336.

Nakhla Olfat E. and Daoud, A.M. (2004): Trial for isolation and characterization of pox virus from turkeys. Egypt. J. Agric. Res., 82 (2): 869-880.

Odend'hal, S. (1983): The geographical distribution of arrival viral diseases. Academic Press, New York, NY.

OIE (2000): Manual of standards for diagnostic tests and vaccines. Fowl pox, Part 3, Section X, Chapter X, 13: 1-10.

Pandey, K.D. and Mallick, B.B. (1975): Cultivation of avian poxes in developing chick embryo. Ind. J. Anim. Hlth., 14 (2): 80-87.

Reed, L.J. and Muench, H. (1938): A simple method of estimating fifty percent end points. Am .J. Hyg., 27: 493-497.

Saini, S.S.; Sodhi, S.S.; Maiti, N.K.; Sharma, S.N. (1990): Immune response of chicks to fowl pox vaccination. Ind. Vet. J., 67 (8): 689-693.

Tripathy, D.N. and Reed, W.M. (1997): Diseases of Poultry. Pox, 24: 643-659.

Winterfield, R.W.; Reed, W.M. and Thacker, H.L. (1985): Infection and immunity with a virus isolate from turkeys. Poult. Sci., 64: 2076-2080.

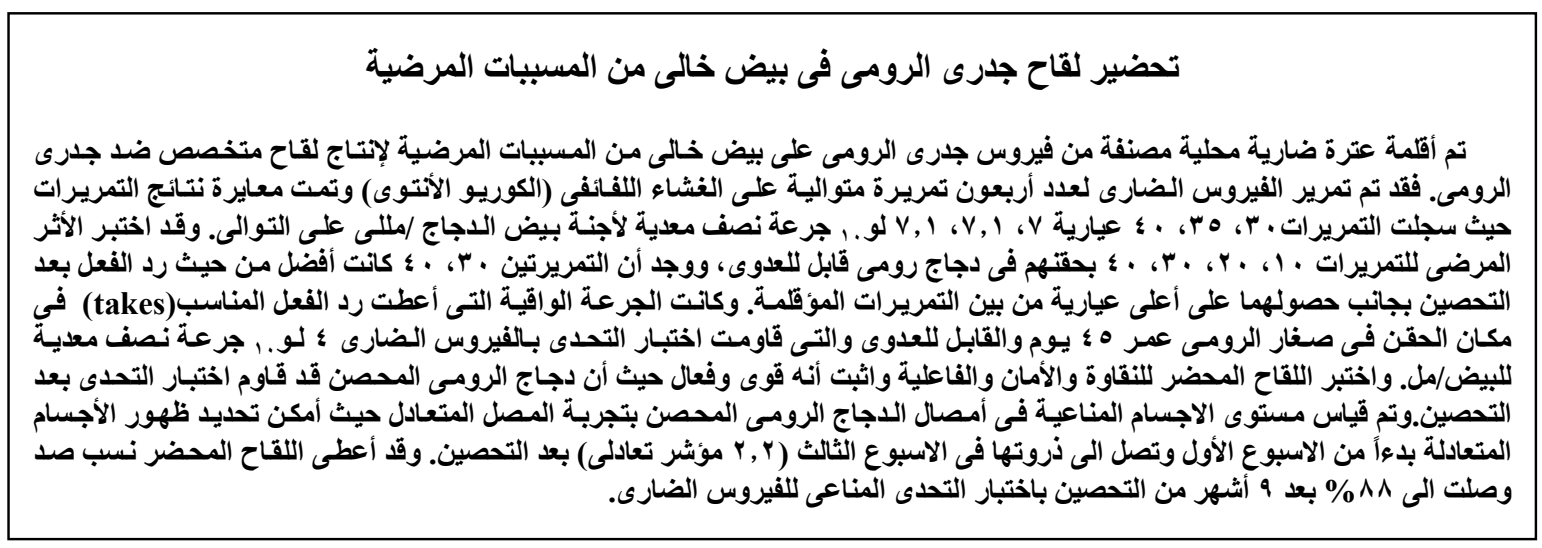


